\title{
Constructing the Training Mode of Public Security Fire Commanders Based on Competency Model
}

\author{
Yi Hou
}

Chinese People's Armed Police Force Academy, Hebei Langfang 065000, China

\section{构建基于胜任力模型的公安消防指挥员 \\ 培养模式}

侯神

中国人民武装警察部队学院, 河北廊坊 065000 , 中国

\begin{abstract}
This paper introduced the competency mode of public security fire commanders, and analyzed the problems existed in the current public security fire commander abilities. Then it proposed the training mode of public security fire commanders based on competency mode. What's more, it also introduced specific components and steps of the training mode: training needs analysis, determination of training content and methods, and training effect evaluation.
\end{abstract}

Keywords: public security; fire commanders; competency; training model

\section{摘要}

本文对公安消防指挥员胜任力模型所包含的因素 进行了介绍, 并结合当前公安消防指挥员能力素质方 面存在的问题, 提出了基于胜任力模型的公安消防指 挥员培养模式, 此外还具体介绍了公安消防指挥员培 养模式具体包含的成分及步骤: 培养需求分析、培训 内容与方法的确定, 以及培训效果的评估。

关键词: 公安; 消防指挥员; 胜任力; 培养模式 1.引言

公安消防部队承担着火灾扑救、应急救援以及重 大活动现场消防勤务等保卫人民生命财产安全的重 要任务, 是我国灭火救援的主力军。作为一支现役部
队, 其灭火救援是在统一指挥下进行的有组织、有目 的的活动, 其成败与指挥员的能力水平密切相关。灾 害和危机具有突发性、复杂性、严重性等特点, 决定 了灭火与应急救援行动的紧迫性、危险性和困难性 ${ }^{[1]}$ 。 通过分析诸多灭火救援案例可知, 指挥员作为灭火救 援指挥的主体, 对于灭火救援活动的成败起着至关重 要的作用。因此, 为了更有效地降低灾害事故带来的 损失及伤亡、提高灭火救援效率, 如何建立一套有效 的公安消防指挥员培养模式, 就成为一项意义重大的 课题。目前, 我国公安消防指挥员的来源多样, 既有 由公安现役院校培养的以战士身份入学的干部, 还有 来自公安现役院校的以高中生身份通过高考入学的 干部, 还有由地方大学生入警、经过消防训练基地短 期培训的干部, 还没有形成一套标准化、规范化的人 才培养体系。本文试图提出一套基于胜任力模型的公 安消防指挥员培养模式, 以期为促进公安消防指挥人 才的培养质量提供一些新的思路和意见建议。

\section{2.公安消防指挥员胜任力模型}

\section{1.胜任力及胜任力模型}

关于胜任力 (competency) 的研究起源于 1973 年, 背景是当时美国政府需要麦克利兰等人帮助他们 甄选外交官, 他们发现通过胜任力模型的方式可以判 断并发现导致绩效好坏差异的关键驱动因素, 麦克利 兰在论文《测量胜任力而非智力》中提及, “胜任力 是包括动机、态度、知识、技能、能力等关键特征在 内的, 能有效区分绩优者与绩平者的一系列特质” ${ }^{[2]}$ 。 
Risk Analysis and Crisis Response in Big Data Era (RAC-16)

而胜任力模型 (competency mode1), 是指组织当中 特定的工作岗位所要求的与高绩效相关的一系列素 质或素质组合 ${ }^{[3]}$ 。

\section{2.公安消防指挥员胜任力模型}

具体采用理论分析与问卷法相结合, 应用测量学 及统计学技术, 编制公安消防指挥员胜任力特征评价 量表, 并通过调查、统计、分析, 运用探索性因素分 析技术构建公安消防指挥员胜任力模型 ${ }^{[4]}$ 。通过调查 研究, 获得了公安消防指挥员胜任力的六因素模型。 获得的六个因素的名称及每个因素包含的项目特征 如下 (按照因素负荷由大到小排序):

（1）认知及情绪意志特征。具体包括: 快速反应 能力、果断的决策力、分析能力强、判断能力强、随 机应变能力强、解决问题能力强、勇敢、沉着冷静、 敏锐的洞察力、思维缜密、具有创新思维、学习能力 强。

（2）知识与技能特征。具体包括: 过硬的消防技 能, 掌握先进的相关技术手段, 具有系统的灭火理论 知识, 熟悉各种灾害事故的处置方法程序, 熟悉辖区 情况。

(3) 组织指挥能力。具体包括: 优秀的组织能力、 指挥理论丰富、协调能力强、能凝聚集体战斗力、语 言表达能力强、有威信、对战士因材施令、能为下属 利益着想, 善于鼓舞士气, 适时激励队伍。

（4）带兵能力。具体包括: 沟通能力强、知道自 己的兵在想什么, 会做思想政治工作。

（5）做事风格。具体包括: 率先垂范、雷厉风行。

（6）职业价值观。具体包括: 荣誉感强、以人民 的生命财产安全为重、热爱消防事业。

\section{3. 公安消防指挥员能力素质存在的问题}

前面提到公安消防指挥员主要由三类人员构成: 一是由公安现役院校培养的以战士身份入学的干部, 二是来自公安现役院校的以高中生身份高考入学的 干部, 三是由地方大学生入警、经过消防训练基地短 期培训的干部。相比较而言, 后两种人没有在消防中 队担任过战斗员或是班指挥员, 对消防部队的情况不 是很了解, 他们缺乏具体消防业务实践的锻炼, 接触 工作时间短, 普遍存在消防业务技能差、管理经验少、 灭火救援指挥能力弱的问题。有的不能很好地组织和 协同部队进行作战; 有的基层指挥员担任中队指导员 却不会上政治课, 不会做深入细致的思想政治工作; 有的不懂现代科技条件下的灭火战术、不能有效驾驭 高新技术装备, 不会科学组织训练; 有的阅历浅、经
验少，适应部队管理的能力弱。

\section{4. 基于胜任力模型的公安消防指挥员培养模式构建}

根据前面的分析, 拟构建基于胜任力模型的公安消防 指挥员培养模式, 主要包括以下成分和步骤:

\section{1.培养需求分析}

所谓培养需求, 是指受训者需要接受哪些培训, 其实质是教育培训对象的素质与某岗位的胜任力素 质之间的差距。在进行公安消防指挥员教育培训之前, 首先需要系统地评估分析参加教育培训的人员在公 安消防指挥员胜任力要素方面的情况, 从而确定是否 有培训的必要或者应该进行哪些方面的培训, 大致流 程包括: 成立培养需求评价小组、采用多种方法对受 训者状况进行评估、找出受训者与胜任力因素之间的 差距并确定培训目标。具体情况如下:

(1) 成立培养需求评价小组。培训需求评价小组 应该由具懂得灭火救援指挥业务的人员参与, 并吸纳 具有心理学、教育学、训练学、基层消防部队工作经 验的人员组成, 任务是负责进行受训人员个人情况的 评估和培训方案的设计, 制定符合科学规律的有效培 养方案。

（2）采用多种方法对受训者状况进行评估。培养 需求评价小组人员可以通过心理测评法、考查法、自 我报告法、观察法、组织评定法等多种方法对受训对 象的情况进行摸底和评估。具体而言, 比如可以使用 心理测评法对受训人员的认知情绪意志特征、做事风 格进行测评; 使用考查法来对受训人员的灭火救援相 关知识与技能水平进行考查; 综合运用观察法、组织 评定法、自我报告法等方法对受训者的组织指挥能力、 带兵能力、组织承诺等方面的状况进行评估。

(3) 找出受训者与胜任力因素之间的差距并确 定培训目标。通过系统评估受训者在胜任力各因素上 的水平, 以确定教育培训的目标和内容, 例如针对没 有当兵经历的来自公安现役院校的以高中生身份入 学的干部, 和由地方大学生入警、经过消防训练基地 短期培训的干部, 就需要着重考虑如何弥补其当兵经 历不足带来的系列问题。笔者建议在院校和基地培养 期间，设置模拟中队，模拟基层消防部队的运作模式 进行管理, 让每个人都有机会体验到 “当战士” 的感 觉, 从而更加理解士兵的心态与想法。再比如, 针对 地方入警大学生灭火救援理论学习时间短的问题对 他们的训练就应该增加理论学习及实践演练的学时, 为其形成扎实的灭火救援理论体系夯实基础。同理, 


\section{Risk Analysis and Crisis Response in Big Data Era (RAC-16)}

也可以结合由公安现役院校培养的以战士身份入学 的干部的特点, 进行入职前培训需求分析。总而言之, 在分析不同群体或个人基本情况的基础上, 有的放矢、 对症下药的进行培训设计。

\section{2. 培训内容与方法的确定}

在对不同受训者培训需求进行分析之后, 就进入 到培训内容的制定阶段。制定培训内容时, 需要针对 不同受训者的培训需求, 突出重点, 体现差异化原则。 针对公安消防指挥员实施的培训内容及方法主要可 以分为以下几个方面:

(1) 心理能力的训练。该部分主要通过心理能力 训练使受训者具备公安消防指挥员胜任力模型中相 应的认知及情绪意志特征。比如, 可以通过一些心理 训练辅助系统, 训练受训者的反应速度与思维能力; 通过案例分析与探讨, 启发受训者的创新思维; 通过 模拟训练设施, 如烟热训练室、灾害现场图片呈现等 方式, 锻炼受训者的心理耐受程度, 使之面对灾害现 场时能够更加冷静沉着、勇敢等。

(2) 知识与技能的训练。该部分可以通过相应的 理论与实践教学, 使受训者掌握系统的灭火理论知识 以及相应的消防技能, 比如灭火战术理论、灭火指挥 理论、灾害事故的处置方法与程序, 辖区的消防水源、 重点单位情况, 消防供水、消防器材的使用等等。

(3) 组织指挥能力训练。组织指挥能力的提高涉 及到到以作战指挥理论知识和技能为主的多学科理 论知识和技能组合而成的知识体系。理论学习、技能 训练是灭火救援组织指挥能力的基础。在此基础上, 可以通过想定作业、战例研究、实兵演练等方式对组 织指挥能力进行实践训练 ${ }^{[5]}$ 。

(4) 提高带兵能力。灭火救援活动的顺利完成有 赖于广大指挥员的密切协调配合。因此, 优秀的带兵 能力是消防指挥员需要具备的重要素质。作为指挥员, 要始终坚持官兵一致的原则, 学会依法文明带兵, 科 学理念带兵, 真挚情感带兵, 良好修养带兵; 要增强 战士主人翁意识, 要善于调动战士的积极性, 始终把 教育人、引导人、帮助人与理解人、尊重人、关心人 统一起来, 激励战士施展才能, 鼓舞战士忠于职守, 强化战士责任感与光荣感 ${ }^{[6]}$ 。

(5) 做事风格的培养。灭火救援指挥活动具有明 显的危险性与时效性, 因此在行为风格上要求消防指 挥员具备率先垂范、雷厉风行的作风, 否则就无法有 效的激励指挥对象或者会错过灭火救援的有利时机。 做事风格可通过长时间抓日常思想教育和训练来养 成。
(6) 组织承诺的培养。通过组织承诺的培养激发 受训者的职业自豪感。可以采用多样的实施方法, 如 采用党课、政治课等政治学习的基本形式; 有针对性 地组织灭火救援现场教育; 通过设计战斗荣誉室, 陈 列有关消防人员的功绩和队史的展览品, 并组织大家 同战斗英雄会见和座谈, 宣传英雄主义、互相救助、 遵守纪律的榜样等等。

培训者应结合被培训者的具体情况, 设计相关培 训内容及其所占比重, 然后围绕不同培训内容采取有 效的方式方法, 以达到最终提高受训者相关能力的目 标。

\section{3.培养效果的有效评估}

为了对教育培养效果进行有效的评估, 可以在教 育培训前建立受训者数据库, 搜集教育培训前后的定 量及定性评价数据, 以便进行前后对比进行效果评估 ${ }^{[7]}$ 。此外, 还可以通过调查受训者的受训感受, 比如 教育训练的满意度, 针对教学师资、内容、方法的态 度及改进建议来评估培训效果, 并结合相关评价结果 逐步对培养模式进行改进和完善。培训效果的评估一 方面是对受训者个人情况的了解掌握, 对于后续的分 岗定职也具有重要意义, 可以为其提供有价值的参考。 另外, 培训评估也是对培养方法有效性的一种评价, 对于改善培训方法、提高未来的培训效果具有重要意 义, 相关部门应给予高度重视。

\section{Acknowledgements}

This study was supported by 2015 Doctors' Creative Scientific Research Foundation of Chinese people's Armed Police Force Academy (No.BSKY201521) .

\section{致谢:}

本研究得到了武警学院 2015 年博士创新科研计划 (BSKY201521))的资助。

\section{5.参考文献}

[1] Zhi Zhang, Jianbo You, Qiaoying Li, Xuan Du. Research Framework for Emergency Rescue of Disasters and Crises. Journal of Risk Analysis and Crisis Response, 2010,11:173-177.

[2] 孙丽. 建立航天科研领域专业人员胜任力模型特 征.华北航天工业学院学报, 2005,15(5):1-6.

[3] 黄云碧,荣鹏飞.胜任力素质研究综述. 商业现代化, 2009, 587:83-84.

[4] 吴明隆. SPSS 统计应用实务. 北京: 科学出版 
Risk Analysis and Crisis Response in Big Data Era (RAC-16)

社,2003.

[5] 何春文.消防部队基础干部素质的培养.河北:中国 人民武装警察部队学院, 2009 .

[6] 评论员.始终把思想政治建设各项建设首位.解放 军报. 1992,(3)

[7] 陈德明,王创.基于胜任力:高校职业指导课教师培 训的新视角.高教探索, 2009,4:93-96. 